\title{
Anomalous Origin of the Right Coronary Artery from the Left Ventricle
}

\author{
Holly M. Ippisch, MD, MS and Thomas R. Kimball, MD, FASE \\ Heart Institute, Cincinnati Children's Hospital Medical Center, 3333 Burnet Ave, MLC 2003, \\ Cincinnati, $\mathrm{OH} 45229$
}

\begin{abstract}
A 22 month old male was referred to pediatric cardiology for evaluation of a heart murmur. He was asymptomatic except for occasional wheezing with activity. On evaluation he was found to have both a systolic and diastolic murmur. An EKG demonstrated possible left ventricular hypertrophy with no evidence of ST abnormalities. An echocardiogram and cardiac catheterization were performed that showed an anomalous origin of his right coronary artery from his left ventricle just inferior to his aortic valve annulus.
\end{abstract}

\section{Background}

Anomalous origin of the coronary arteries are rare but are known to occur in some typical forms including anomalous origin of the left coronary artery from the: 1) pulmonary artery, 2) right coronary artery, and 3) right sinus of Valsalva. ${ }^{1}$ The right coronary artery is known to arise anomalously from the: 1) left main coronary artery, and 2) left sinus of Valsalva. ${ }^{1}$ There are also various coronary artery fistulous connections that have been documented and typically include fistulous connections from the right or left coronary artery to low pressure chambers such as the right ventricle and pulmonary artery. ${ }^{1}$ We report an unusual case of a patient whose right coronary artery originates from the left ventricular cavity, just inferior to the aortic valve annulus.

\section{Case Report}

A 22 month old male was referred to pediatric cardiology for evaluation of a heart murmur. He was asymptomatic except for occasional wheezing with exertion. Family history was negative. Growth and development were normal. On physical exam the weight was $15.7 \mathrm{~kg}$ $\left(97^{\text {th }}\right.$ percentile), and the length was $86 \mathrm{~cm}\left(>50^{\text {th }}\right.$ percentile). The blood pressure in the right arm was $96 / 62 \mathrm{mmHg}$, and in the left leg was $94 / 48 \mathrm{mmHg}$. On cardiac auscultation there was a II-III/VI systolic ejection murmur followed by a II/IV diastolic descrescendo murmur at his right upper sternal border. The distal pulses were normal. The EKG showed possible left ventricular hypertrophy with no evidence of ST segment abnormalities. An echocardiogram

(C) 2009 American Society of Echocardiography. Published by Mosby, Inc. All rights reserved.

Address for correspondence: Holly M. Ippisch, MD, MS The Heart Institute Cincinnati Children's Hospital Medical Center 3333 Burnet Ave, MLC 2003 Cincinnati, OH 45229 Holly.Ippisch@cchmc.org Office phone: (513) 636-3864 Fax: (513) 636-7117.

Presented in part at the $16^{\text {th }}$ Annual Scientific Sessions of the American Society of Echocardiography, Boston, MA, June 17, 2005.

Disclosures: The authors have no conflicts of interest to disclose. There are no other financial disclosures.

Publisher's Disclaimer: This is a PDF file of an unedited manuscript that has been accepted for publication. As a service to our customers we are providing this early version of the manuscript. The manuscript will undergo copyediting, typesetting, and review of the resulting proof before it is published in its final citable form. Please note that during the production process errors may be discovered which could affect the content, and all legal disclaimers that apply to the journal pertain. 
was performed which demonstrated that the origin of his right coronary artery was from his left ventricle, just inferior to the aortic valve annulus. (Figure 1, Video 1) There was retrograde flow from the right coronary artery coursing into the body of the left ventricle. (Figures $2 \&$ 3 , Video $2 \& 3$ ) The left coronary artery originated normally. Both coronary artery systems were diffusely dilated.

A cardiac catheterization was performed for further delineation of the anatomy and hemodynamics. The left ventricular pressure was $84 / 10$, and the remainder of the hemodynamics were normal. A selective contrast injection into the left main coronary artery demonstrated antegrade filling of the left coronary artery system coursing via collaterals to retrograde filling of the right coronary artery system with subsequent emptying into the left ventricle. (Figure 4, Video 4)

\section{Discussion}

The patient remained asymptomatic without treatment. No surgical intervention was performed. To our knowledge this diagnosis has only been presented in two previous case reports. One case was in a 64 year old woman whose diagnosis was an incidental finding at the time of an aortic valve replacement for aortic stenosis. She subsequently underwent bypass grafting. ${ }^{2}$ The other case was also unrecognized pre-operatively. She was a 4 month old infant with congenital valvar aortic stenosis who underwent surgical aortic commissurotomy in 1995. She died on the operating table when her left ventricle failed to recover at the end of her operation. Her coronary anomaly was discovered at autopsy. ${ }^{3}$

As currently seen in these case reports, the exact origin and course of coronary arteries can be a difficult diagnosis. The confirmation of this diagnosis in children typically requires a very cooperative or sedated child to obtain adequate echocardiographic images for evaluation. In addition, despite the most ideal situations, the images can be misleading due to deficiencies in lateral resolution which may create drop-out giving the false impression of a normal coronary ostium. The use of color Doppler is essential in confirming the exact origin and flow patterns of the coronaries. In addition, the detection of retrograde filling of the coronaries can be particularly helpful in suspecting coronary anomalies. Although as seen in this child, retrograde color flow into the left ventricle can also be mistaken as aortic insufficiency if there is not a high level of suspicion. In addition, the combination of drop-out and abnormal coronary flow patterns near the main pulmonary artery may lead some to incorrectly suspect a more typical anomalous origin from the main pulmonary artery.

Although the origin of the RCA from the left ventricle is an extremely rare coronary artery anomaly, it is important to consider it in the differential when evaluating anomalous coronary arteries and unexplained regurgitant jets into the left ventricle.

\section{Acknowledgments}

We would like to acknowledge the following person for his contribution: Russel Hirsch, M.D. (cardiac catheterization image). This study was financially supported in part by the following NIH grants: T32-ES10957 and K23-HL091174.

\section{References}

1. Snider, AR.; Serwer, GA.; Ritter, SB. Echocardiography in Pediatric Heart Disease. 2nd ed. Mosby Year Book; St Louis: 1997.

2. Okuyama M, Kubota I, Miura T, Nagamine S, Yokoyama K. Anomalous Origin of the Right Coronary Artery from the Left Ventricle in an Adult. Jpn Heart J 1995;36(1):115-8. [PubMed: 7760508] 
3. Culbertson C, DeCampli W, Williams R, Helton G, Young N, Hardy C. Congenital Valvar Aortic Stenosis and Abnormal Origin of the Right Coronary Artery: Rare Combination with Important Clinical Implications. Pediatr Cardiol 1995;16:73-75. [PubMed: 7784238] 


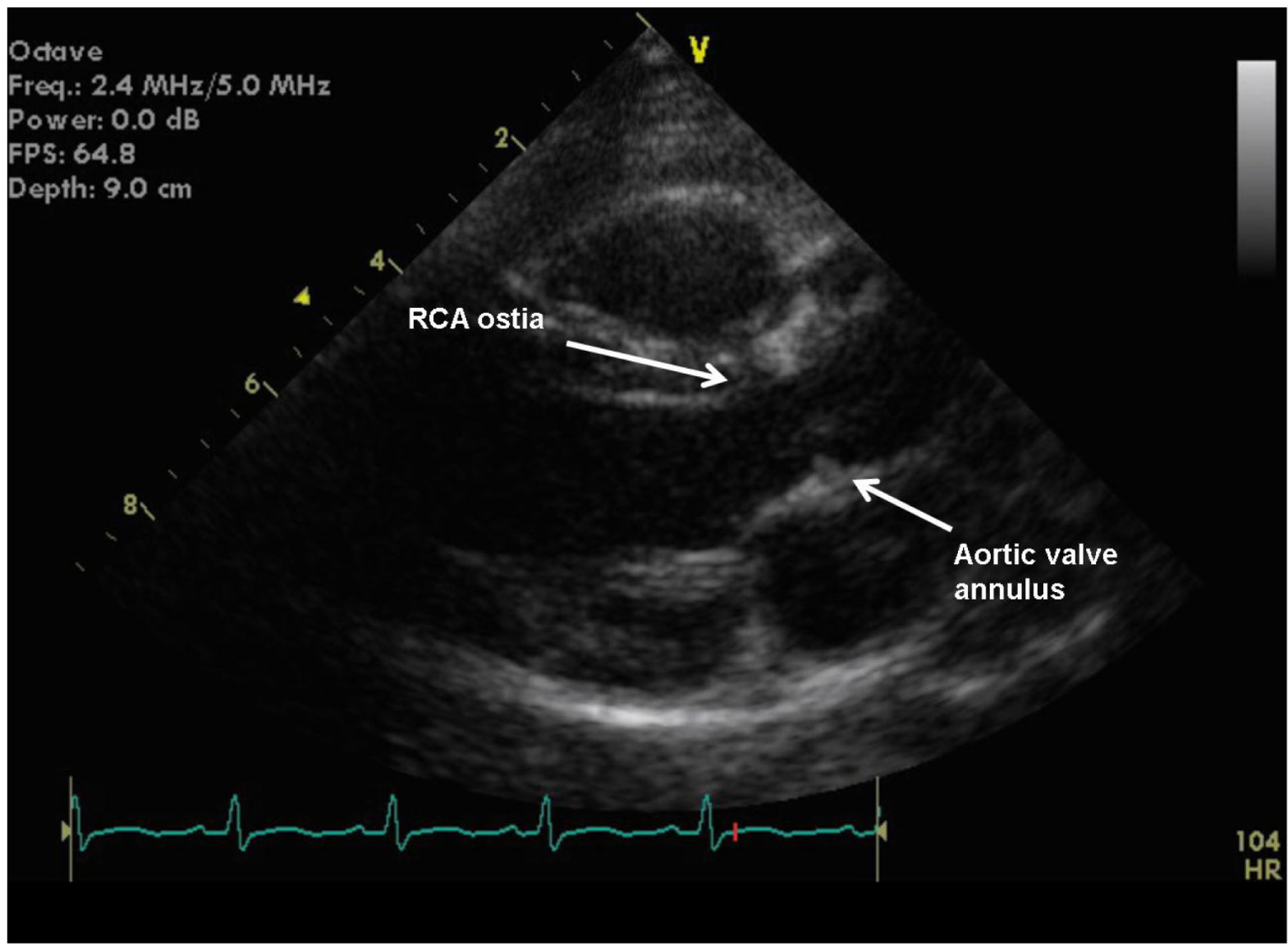

Figure 1 (Video 1).

Parasternal long axis: Arrow points to the right coronary artery (RCA) originating from the left ventricle just inferior to the aortic valve annulus. 


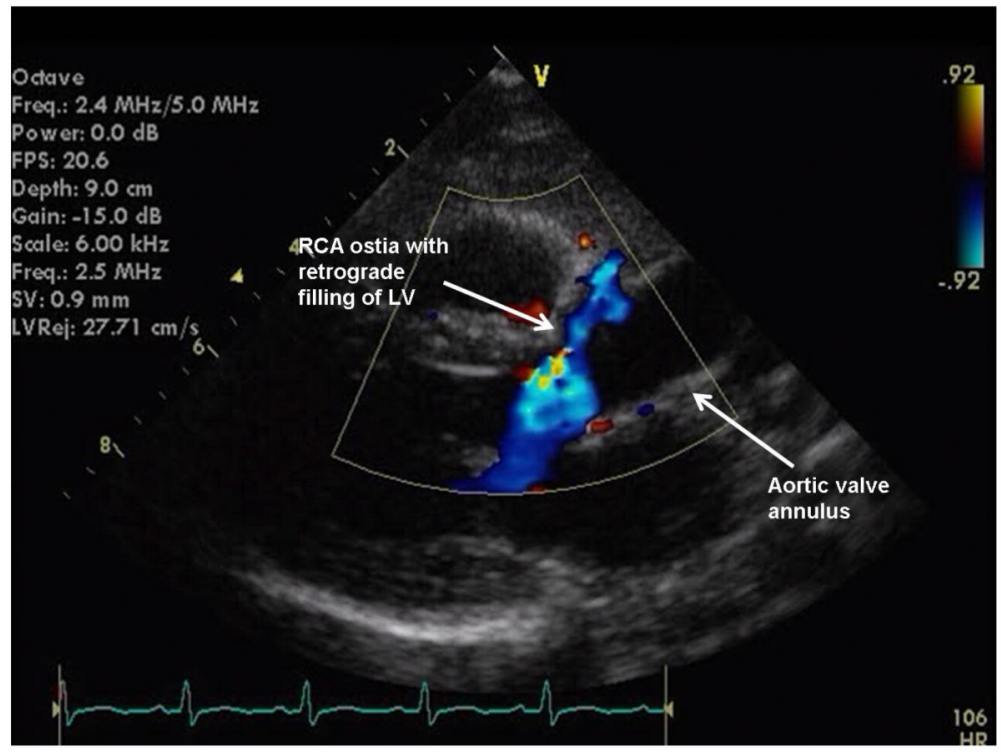

Figure 2 (Video 2).

Parasternal long axis with color Doppler flow: Blue jet of color represents blood flow coursing retrograde thru the right coronary artery (RCA) and emptying into the the left ventricle (LV). 


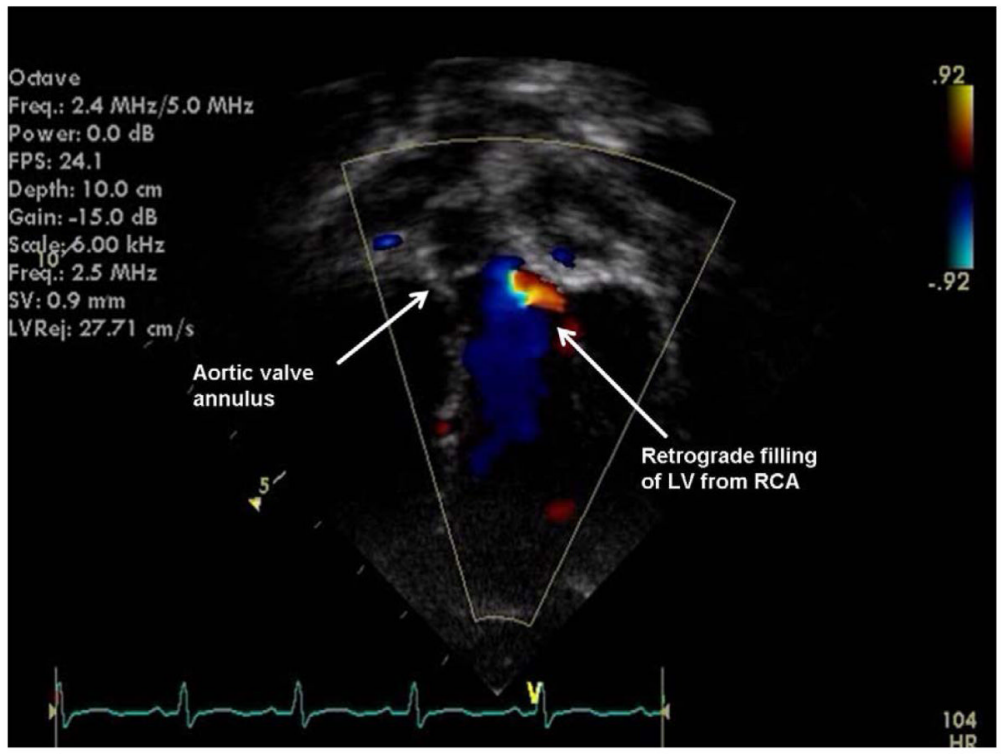

Figure 3 (Video 3).

Apical 5 chamber view: Red jet of color Doppler demonstrates retrograde flow from the right coronary artery (RCA) in to the left ventricle ( $\mathrm{LV})$. 


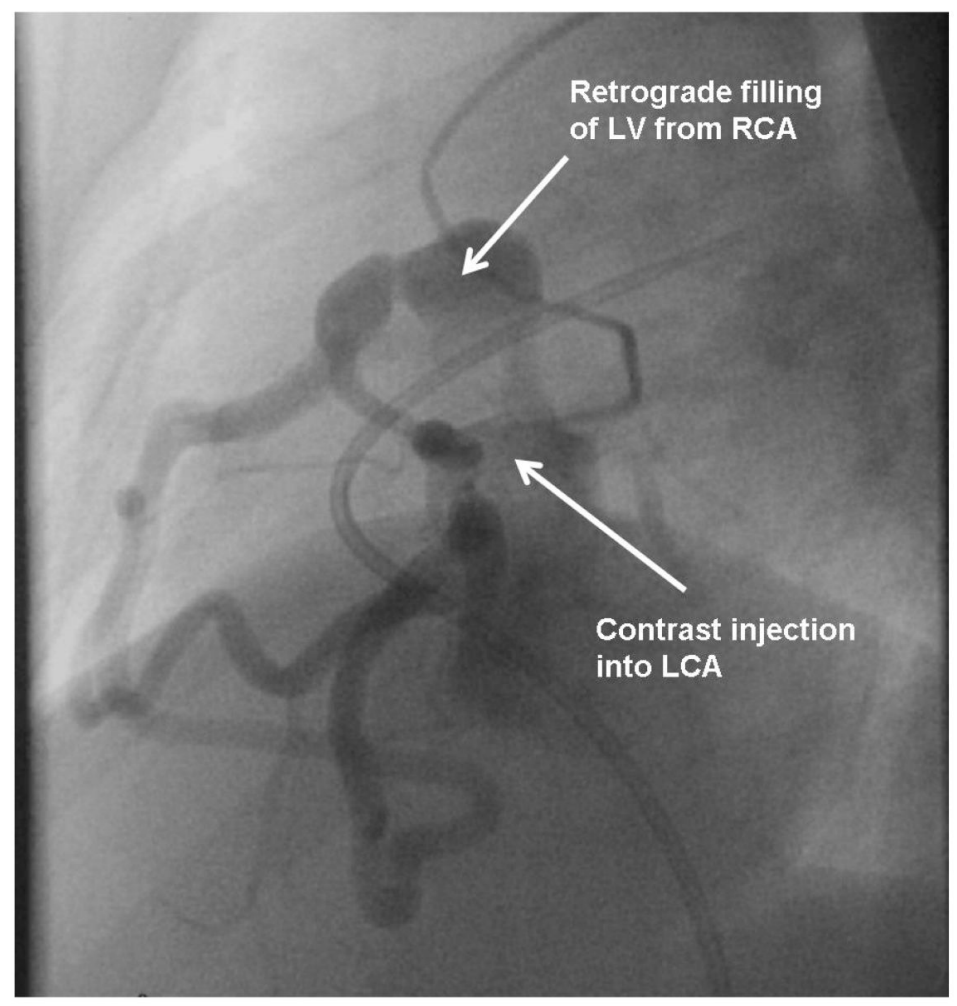

Figure 4 (Video 4).

Cardiac catheterization angiogram, lateral view: Injection in the left coronary artery (LCA) ostia with a 4 French $2.5 \mathrm{JL}$ coronary catheter demonstrates antegrade filling of the LCA and retrograde filling of the right coronary artery (RCA) via collaterals, with subsequent emptying into the left ventricle (LV). 